Conclusions Findings from this study can help these actors devise strategies to promote road safety in Turkey or in other similar contexts.

\section{EVALUATION OF THE STATE OF CITIZEN SAFETY IN FINLAND}

Teija Mankkinen. The Finnish National Rescue Association, Finland

\subsection{6/injuryprev-2016-042156.506}

Background The concept of safety has traditionally been limited to physical security. However, in the 2000s the concept has been expanded to cover also the aspects of social, economic and environmental wellbeing (Kekki 2015). The promotion of safety and security in a global world requires more comprehensive and multi-sectoral cooperation, but also broader and more cross-sectoral information on issues preventing or promoting safety.

Methods The presentation reviews the previous research data available on the topic. Also, the presentation summarises the current state of the citizen safety from the perspective of the previous research and discusses the possible gaps concerning the produced data. The review is based on the data consisting of the previous administration-specific security and safety surveys and studies as well as national surveys.

Results A number of surveys are available on the topic, but most of them define the research topic quite narrowly from the perspective of certain administrative bodies. Only a small amount of data is found on citizen's abilities or opportunities to promote their own safety. Hence, there is also a lack of standardised evaluation criteria for (measuring) citizen safety. In addition, the comparability of data is difficult due to differing definitions of the concepts which are used and the limitations concerning different research settings.

Conclusions The future decision-making needs to be supported by diverse, cross-administrative information about citizen safety and the issues related to security and safety in general. Indicators formed to monitor the development of citizen safety are presented as the conclusions of the presentation.

\section{POLISH ROAD SAFETY OBSERVATORY AS A TOOL FOR EFFECTIVE ROAD SAFETY MANAGEMENT AND POLICY DEVELOPMENT}

Maria Dabrowska-Loranc, Dagmara Jankowska-Karpa, Justyna Wacowska-Slezak, Aneta Wnuk. Motor Transport Institute, Poland

\subsection{6/injuryprev-2016-042156.507}

Background In 2014 Motor Transport Institute established Polish Road Safety Observatory POBR according to the recommendations of National Road Safety Programme GAMBIT 2005-2007-2013 and the assumptions of European Projects SafetyNet and Dacota.

Methods The overall objective of POBR is to contribute to a reduction in the number of road accident victims in Poland. To achieve this goal it is important to provide information about risks on Polish roads and disseminate knowledge concerning road safety. The basic tasks of POBR are as follows: disseminating road safety knowledge, data and information collection and sharing, conducting analyses and research, evaluating programs and activities implemented, cooperation with Regional Road Safety Observatories and other institutions.
Results A reliable road accidents database is essential to identify major problems with regard to road safety. It is also a starting point to plan preventive actions and the source of information in the evaluation process. The accuracy of decisions and the improvement of road safety situation largely depend on the scope and quality of gathered data and conducted analyses. POBR provides national data on road accidents, general population, driver population, vehicle fleet, road network, area. International data are obtained from CARE, OECD, IRTAD and EUROSTAT databases. The data and information in POBR are intended for state and local authorities, road managers, experts from various disciplines, local communities, media, general public and international institutions.

Conclusions The main aim of POBR is to contribute to planing and evaluating knowledge and evidence based actions. POBR can serve as road safety management tool and be useful for road safety policy development. POBR system consists of data warehouse and information portal. An important element of the system is an application, which is designed to create thematic and risk maps which allow the identification of dangerous road sections.

\section{HEALTH IMPACT OF SOBRIETY CHECK POINTS IN MEXICO CITY}

Lourdes Gómez-García, Elisa Hidalgo-Solórzano. Center for Health Systems Research, National Institute of Public Health, Mexico

\subsection{6/injuryprev-2016-042156.508}

Background Random breath testing for vehicle drivers is a costeffective and widely recommended intervention to address drinking and driving. Since September 2003, in Mexico City were implemented random sobriety checkpoints. In 2008, Mexico City joined a comprehensive intervention program, the "Iniciativa Mexicana de Seguridad Vial" (IMESEVI), which also targeted drinking and driving. The aim of this study is to assess the impact of the sobriety checkpoints on rates of collisions and injuries.

Methods We conducted a secondary analysis of official databases on mortality rate, hospital discharges rate, and collisions rate. Information was collected in the period from January, 1999 to December, 2014. We performed a time-series analysis to assess the trend. Twelve month seasonality was considered and the implementation of the IMESEVI in the city.

Results We observed different effects in the monthly trend associated with the implementation of sobriety checkpoints in interaction with IMESEVI. A no significant decrease $(p>0.05)$ was observed for mortality rate $(-0.05$ deaths per 100,000 inhabitants) and hospital discharges rate ( -0.02 discharges per 100,000 inhabitants). The monthly trend for crash rate had a no significant increase $(p>0.05)$ : 0.14 crashes per 100,000 inhabitants per month and 0.41 crashes per 100,000 vehicles per month.

Conclusions Drinking and driving law enforcement in Mexico City is strongly implemented and socially accepted. Despite, legal blood alcohol concentration (BAC) is $0.08 \mathrm{~g} / \mathrm{dl}$, above the recommended $0.04 \mathrm{~g} / \mathrm{dl}$. In order to improve drinking and driving legislation, and obtain better results for sobriety checkpoints, legal BAC levels must be adjusted and zero tolerance for novice driver may be included in the legislation. To improve the evaluation of alcohol consumption deterrence interventions, official registries may include alcohol consumption information. 